\title{
Analysis of human resource integration in the China's investment in Thailand on the perspective of culture
}

\author{
Yan Li* \\ International Business School \\ Yunnan University of Finance and Economics \\ Kunming, China \\ cyliyan2002@163.com
}

\author{
Lin $\mathrm{Su}$ \\ International Business School \\ Yunnan University of Finance and Economics \\ Kunming, China \\ 939034190@qq.com
}

\begin{abstract}
With the deepening of economic globalization, foreign direct investment has gradually become the mainstream. In recently years, with a large number of China's investment in Thailand, the question of human resource integration in the transnational corporation has been highlighted. The cultural differences between China and Thailand seem to be one of the main factors which influence the human resource integration in the multinational corporation. The purpose of this paper is to analyse the human resource integration in the China's investment in Thailand on the prospective of culture. Through analysis of the influence of cultural differences between China and Thailand on the human resource integration in the overseas investment enterprises, it is found that choosing appropriate cultural management mode, designing the organization structure adjusted to cultural difference, and setting up the mechanism of cross-cultural communication will be good to provide the integration strategy of human resource, including recruitment mechanism, performance evaluation and incentive mechanism, training system, and the integration of compensation and welfare system.
\end{abstract}

Keywords-Yunnan enterprises; engineering; contracting markets; risk ;

\section{INTRODUCTION}

According to the data of China's ministry of commerce, it shows that the top five ASEAN countries which China invests in at present are Singapore, Myanmar, Indonesia, Cambodia and Thailand, as is shown in figure [1]. There are many advantages when China invests in Thailand. However, direct investment in Thailand from Chinese enterprise is far behind other countries both in quality and quantity. The data released from the national bank of Thailand in February 2011 shows that working as the 11th Thailand's major foreign investor, the amount of China's investment in Thailand is 2.168 billion baht in 2010 , which accounts for $1.29 \%$ of total foreign investment in Thailand [2]. Although some enterprises have obtained the success, few of them could be in a sustainable and stable development, which is a phenomenon worthy of deeply thinking. Based on the perspective of culture, by comparing the cultural differences between China and Thailand. this article analyzes its influence on the human resources in the Chinese enterprises investing in Thailand.

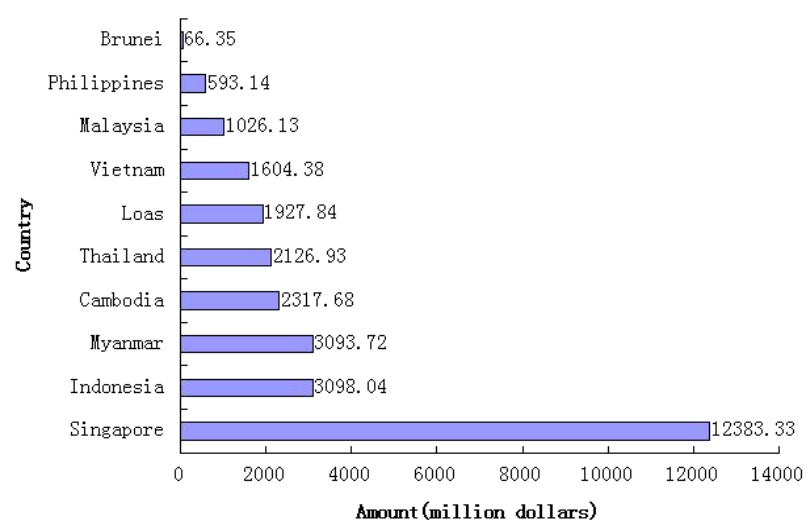

Fig. 1. Cultural differences's influence on the human resources in the Chinese enterprises investing in Thailand.

\section{The INFLUENCE OF CUlturAl DifFERENCES BetWEEN ChInA ANd ThaIland ON THE Human ResourCe INTEGRATION IN THE OVERSEAS INVESTMENT ENTERPRISES}

A. The influence of culture on the management of human resource integration

By taking Hofstede's research method of cultural differences and using the national culture model, this article measures cultural differences from five value dimensions [3]:

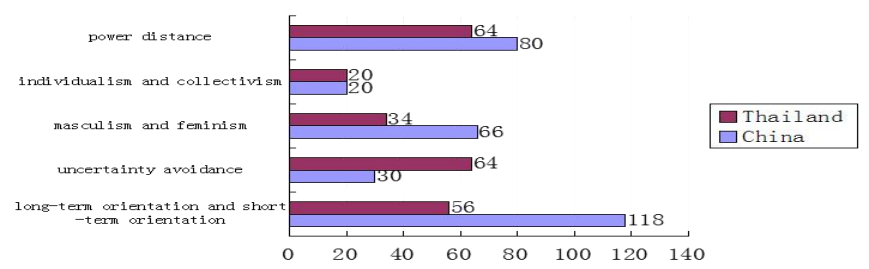

Fig. 2. Data comparison of human resource management between China and Thailand enterprises on the five dimensions 


\section{1) Power distance}

As shown above, we can see that Thailand and China both belong to countries with high power distance, but Thai power distance index is slightly lower than China's. This data means that in the Thailand and Chinese enterprises, subordinates have very strong dependence on the superior, there is a strong right concentration, and organization structure tends to relatively vertical. The symbol of privilege and status is to be accepted by people, and the ideal boss is a benevolent dictator.

Thailand is a country with strong hierarchy. In the hierarchical society, the selection and decision is based on the social class of candidates. People think that social hierarchy is good for people. Subordinate depend on the hierarchical relationship, and can be content with the status quo. The liquidity of stuff is usually small, and they generally don't challenge to the social hierarchy or high power.

China, as a large power distance country, people are not equal. Command delivery is from top to bottom, and centralization is popular. People accept the value of authority, and there is a large wage gap between upper and lower class in a company.

\section{2) Individualism and collectivism}

According to the above, we can see that Thailand and China both belong to the collective countries. Living in this collectivist cultures, people tend to emphasize collective belonging, emphasize the thinking of "collective". Individuals is seen as one part of group, so they must obey collective requirements, at the same time, they are stimulated by the collective goals and strategies, rules and regulations, and other incentives.Due to the Thai buddhist culture, person exists in the society as a member of family and community. Group protects them and members in turn give loyalty. When Thai people are considering problems, the starting point of making a decision is "we". Thai people pay attention to the group membership, interpersonal relationships. People should not only focus on their own emotions, and had better pay attention to the feelings of people around you. They are trying to keep some harmonious and peaceful life.

The mainstream in the Chinese mind is still the collective interests exceed personal interests, and the value of individual existence is manifested by the collective. Chinese also lay emphasis on the emotional communication among people, rather than independent existence.

\section{3) Masculism and feminism}

From the above chart, it can be learned that Thailand and China are quite different in this cultural dimension.

Thailand tends to a feminine society. Buddhism does not encourage competition, so the Thai people think highly of leisure and often do not have too big ambitions [4]. Easy job with moderate income is considered better than hard work with high salary. With smaller working pressure and less labor conflicts, Thai attach importance to equal, united and friendly atmosphere, and the safety of employees, so that they pay more attention to the quality of working life. In the Thai people's core values, considering the needs and feelings of others is more significant than money.
China prefers to a masculine society. Since success and money are viewed as the most valuable things, it is believed that men should be decisive, brave and ambitious. Chinese attach great importance to the income, social identity, achievements and challenges, so that working pressure is relatively high, and they emphasize fairness, competition and results [5].

\section{4) Uncertainty avoidance}

As seen above, it can be learned that there are some difference in this cultural dimension between Thailand and China. Compared with China, Thailand has a higher tendency of uncertainty avoidance.

Faced with uncertain things, Thailand's enterprises will try to avoid uncertainty and ambiguity, and adopt conservative avoidance policy. Enterprises usually make strict rules and regulations, make sure internal responsibility. They regard expert opinions as important, and their organization presents a highly formalization, classification and institutionalization, in order to deal with the uncertainty in the environment. They would not like to do business with people whom they are not familiar with, are cautious in dealing with problems and are not willing to take risks.

China seems to be similar to Thailand at this point. It is considered that the more rules and regulations are, the better the companies are. Managers and employees are accustomed to lay down the specific detail regulations in advance, in order to cope with the possible uncertain factors at work. With the opening of China's economy, Chinese enterprises have a lower uncertainty avoidance than Thailand. Chinese like to innovate, can accept unusual ideas, and gradually improve the ability to bear the risks of uncertainty.

\section{5) Long-term orientation and short-term orientation}

According to the above, we can conclude that the difference between China and Thailand is extremely large on this cultural dimension.

Thailand's long-term orientation is low, because some Thai people love American ideas of consumption ahead of time. They are satisfied with ease at home and enjoy life. They treat the concept of time value is emphasizing now, staff can leave company at any time going on a holiday until the salary is little. They think that time is not necessarily used to make a living, and success depends on luck rather than timing, so they lack the concept of time is money, time is efficiency.

China belongs to the typical long-term orientation country. Following the sustainable and development path, Chinese always plan for the future early. For example, Chinese like to save money, and do not consume in advance; they pay more attention to long-term and stable relationship among people. In the international business, Chinese emphasis on mutual trust and long-term relationships rather than money at the moment, and take employee's potential into account [6].

This cultural dimension has a certain guide and distinction in the human resource integration management, such as recruitment system, training system and other aspects in the overseas investment enterprise. 


\section{$B$. The recruitment system under the cultural differences between China and Thailand}

A country's law and culture affect people's expectations, and point out the "correct" method when managers are looking for new employees. Western prefer to science, evaluate candidates with various specifications (e.g., EQ, IQ tests, etc.), and think that ability is greater than morality, so that the role of a person at work is objectively evaluated. Oriental tend to the rule of men. Especially during the interview, the interviewer's randomness is larger, and think highly of morality rather than capacity. So next this article will use culture theory of five dimensions to concretely analyze the recruit system under the cultural differences between China and Thailand.

1) In the high power distance countries, the companies is given priority to candidates' qualifications during the process of recruitment, and they believe degree is greater than capacity[7].

They think applicants from famous universities, either have the innate technical talent, or have the rich knowledge and experience after learning and working. China and Thailand both belong to high power distance countries, but China is slightly higher than Thailand. Besides moral background and qualifications, companies will care about the candidate's political quality.

2) In collectivism-oriented countries, enterprises tend to hire staff from their familiar group.

The characteristics are embodied in the family-owned company or personnel nepotism. Owing to China and Thailand being collective countries, although modern enterprise system is implemented, there are still a lot of rules of men in the recruitment process.

3) Thailand belongs to the feminine society, so nature of work has little relationship with gender.

Because work is not the core of people's life, people demand more leisure time. On the contrary, China belongs to masculine society, different works emphasize different genders. Work is regarded as the core of people's life. For example, people often spend a lot of time on the job, pursue higher income and like challenges, and view the success of work as the success of life.

4) Thailand is one of high uncertainty avoidance countries, the recruitment of new staff mainly rely on the degree of their adaptation and loyalty to the organization, the depth of the qualifications, the long-term commitment to the organization and so on.

Compared with Thailand, China belongs to the low uncertainty avoidance country, the level of education, work experience, career will become the basis during enterprise's recruitment of personnel.

\section{5) Thailand belongs to short-term oriented country.}

Company requires the candidates' work skills which can be applied directly at work and focuses on short-term returns. China belongs to the typical long-term oriented country. Recruitment is based on the applicant's personality needed to be adapted to the company culture and level of education. Ranks high in the world, China's long-term orientation requires enterprises to supply employees with a long training cycle, so this lead to a considerable huge recruitment of graduating students.

\section{The training system under the cultural differences between China and Thailand}

The type and quality of labor force used in a company is an important factor in human resource management. A country's education system provides the initial state of human resources for the company. Company's training for employees acts as a necessary condition to determine if a person can become a qualified employee.

1) In high power distance countries, the training will focus on obedience and trustworthiness.

China and Thailand belongs to this kind of countries. Employees in both countries have already become accustomed to the transmission of command from top to bottom and employees' enthusiasm and participation is not high [8].

2) In a highly collectivist country, employee passively accept company arrangement of training, whose goal is to meet the company's demand for skills.

As a result, employees often passively wait for training and its purpose is to improve production efficiency of the whole group.

3) In the feminist Thai culture, work is not the core of life, and people concentrate on the quality of life.

While in the masculist Chinese culture, work constitutes the focus of people's life. work recognition is considered to be inspiring, so companies will often organize the training, whose content is related to employees' career development.

4) Thailand tends to high uncertainty avoidance culture.

The focus of employees' training is on improving the staff's professional level and avoiding fierce competition, so as to obtain a sense of security. China tends towards low uncertainty avoidance culture. The company emphasizes more adaption from staff training, and encourages employees to continuously innovate.

5) In the short-term oriented culture, corporate training mainly concentrates on the skills needed in the company's production and operation activities recently, so does Thailand.

In long-term oriented culture, training centers on the basic skills needed for employees' long-term employment. Chinese companies with long-term orientation, are more willing to cultivate the moral concept and sense of belonging of employee, who are consistent with the company culture, so as to obtain the long-term economic benefits.

\section{The performance evaluation system under the cultural differences between China and Thailand}

Performance appraisal is a process of evaluating employees' contribution to the organization in a given period of time. Enterprise's performance evaluation system works as an important element in the control system of organizational structure. Therefore, how to assess people from different cultural background has become one of the major challenges in 
the human resource integration and management of multinational enterprises.

1) In the high power distance countries, such as Thailand and China, there is difficulty to set the company's performance evaluation index.

Basic reason lies in management right is relatively bigger, ordinary employees will not be involved in the process of making evaluation index, and subordinates will only wait for work arrangement from boss. If managers delegate to make performance evaluation index together with their staff, this is seen as the managers' incompetent or employees' unauthorized behavior, so employees participation is extremely low.

2) In Thailand and China who have the collective tendency, the evaluation system of individual work performance cannot be open and impartial like individualism society.

In collective countries, employees' existence comes from community. Emphasis on individual performance appraisal is trying to separate employees and group, therefore, collective appraisal is better than individual assessment.The performance evaluation system tends to be informal manner.

3) As the feminist country, Thai staff performance appraisal system don't distinguish gender.

Enterprise will carry on the appraisal according to employee's performance. As the masculist country, gender differences will lead to different evaluation index in Chinese companies.

4) As one of high uncertainty avoidance countries, Thai employees have a tendency to high risk aversion, and are not willing to take on the challenging work, which brings the difficulty for the company in the setting of performance evaluation indicators, thus the appraisal is based on the employees' qualifications and loyalty to companies.

By contrast, China belongs to low uncertainty avoidance country. Although there are seniority phenomena in the performance appraisal, companies are learning from western step by step, evaluating on a basis of employees' outstanding performance.

5) In Thailand with short-term orientation, performance appraisal system tends to evaluate work performance in the near future.

In China with long-term orientation, the core of evaluation system is to assess the "whole person" who is in line with the companies' long-term development, that is to say, while company is evaluating staff's job performance, working attitude and loyalty are also considered.

\section{E. Compensation system under the cultural differences between China and Thailand}

Compensation refers to the various types of reward to employee as individual labor return. Compensation management system is a thorny problem in the human resources integration of overseas investment. Good and effective compensation management is beneficial to improve employees' job satisfaction and job performance, enhance enterprises' competitiveness in the market, and promote longterm and effective development of enterprise. But under the different cultural differences, there is a big difference in the compensation system.

1) In high power distance countries, such as Thailand and China, there is a very big income gap between the top personnel and subordinates in a company.

Salary system reflects the hierarchical concept and staff position within the company.

2) Thailand and China with collective culture, compensation system is based on group performance and bonuses are distributed based upon collective units, such as "excellent working group" as a collective honor.

3) As the feminist country, Thai people long for more leisure time, and don't want to sacrifice their relaxed time to increase income, in this case, their salaries have little difference.

As the masculist country, the recognition of work will be regraded as the realization of value of life, hence, they are willing to work for a longer time, and is reluctant to give up any possible wage income.

4) In Thailand with high uncertainty avoidance culture, the determination of salary is on the basis of employee's qualifications and expertise.

Qualified and expert employees may bring more benefit. Since older employees are familiar with business, they also can make a greater contribution to the company. China has a lower uncertainty avoidance than Thailand, the compensation care not only about seniority, but also about outstanding performance. The latter always brings additional salary to staff.

5) In Thailand of short-term orientation, the expectation wage of employee is linked with his short-term skills.

In China of long-term orientation, compared with current salary, personal future career and the long-term development of company are attached more importance to. People give priority to the job security and stability.

\section{The STRAtegy of Cross-CUlture Human Resource INTEGRATION}

Thailand and China are both Asian countries, but as stated earlier, due to the different history and geography environment, there are significant cultural differences between the two. This paper puts forward some countermeasures for Chinese enterprises investing in Thailand, which can be applied in the process of integrating human resources.

\section{A. Choose the appropriate cultural management mode}

Through the above comparison, China's enterprises investing in Thailand are suitable to adopt collaborative culture management mode. In the process of human resources integration, multinational company will face the culture collision between the two countries. Companies neither take Chinese culture as a ruler, and are above Thai culture, nor take the way of compromise and concession, to intentionally avoid cultural differences. The correct approach should be to find the similarities and differences between the two cultures, then 
make organic integration as a whole, in order to form a new enterprise culture. Every employee can follow the common values, and takes action which is beneficial to company's longterm development. Only in this way, the multinational companies can be able to run continuously in the host country.

\section{B. Design the organization structure conforming to the cultural differences}

When enterprises invest abroad, the setting of organizational structure is crucial, which affects the running efficiency of the whole company, from the decision making, command transmission to the execution of employees. Thailand is a country which emphasizes hierarchical concept, and people rely on hierarchy. Therefore, enterprises should emphasize the formal organizational structure, and maintain stability in each class, which could not change over time. This hierarchy is established on the basis of the detailed labor division, and is similar to a pyramid structure. In such a culture, this kind of organizational structure seems to be more likely gain the recognition of management and ordinary employees, and achieve good operating efficiency as well.

\section{Establish the cross-cultural communication mechanism}

After Chinese companies invest in Thailand, the crosscultural communication problems widely exist among Chinese and Thai employees. Enterprises should strengthen the construction of formal communication channels, such as internal document delivery, conference holding, information exchange and so on. What's more, they should also attach importance to opinions exchange, friends' party and other informal communication channels, create a loose and free environment, and form the open and free communication system. In addition, enterprises should pay more attention to cross-cultural communication feedback mechanisms, such as the establishment of dialogue mechanism for employees, or employees' questionnaire survey system. Through effective cross-cultural communication, it can dissolve cultural differences and improve employees' satisfaction, which is good for culture integration and human resource integration in multinational enterprises.

\section{Recruitment system integration}

Primary challenge of enterprise personnel system is staff recruitment, promotion, training, evaluation and other challenging integration task under different cultural backgrounds.

Personnel arrangement has been given priority to localization, and supplemented by diversification. First of all, the localization. It can reduce the high costs of enterprises' expats, and give full play to the local people's media role in cultural integration. Second, the diversification. In order to transfer the company's core technology, it needs to send staff from headquarters. These expatriates help communicate smoothly between subsidiaries and parent company, thus, the core advantage can be transferred effectively. In addition, multinational companies need to select and recruit outstanding employees worldwide, concentrating on his position matching and diluting his nationality.

\section{E. Performance evaluation and incentive system integration}

When multinational corporations are making performance evaluation and incentive system, only combining members personal career with the enterprise's long-term development together to can make their dedication to the enterprise.

Firstly, we should set up reasonable performance appraisal system. It had better been distinguished by the business environment of host country and the characteristics of internal policies of subsidiary, which also need meet the qualitative, quantitative and objective requirement. Secondly, we should establish a variety of incentives. By holding different values, employees usually center on different things. For instance, Thai prefer to enjoy leisure vacation other than gain work achievements and wage subsidies, While, performance targets are effective incentives to Chinese employees.

\section{F. Compensation and welfare system integration}

The compensation system, structure and levela exist significant differences in the home country and host country' enterprises. Enterprises in overseas investment had better take advantage of different salary strategy, internal talent orientation, external talent market and competitors remuneration strategy in different periods, all of which will influence on the integration of its compensation system.

First of all, the salary system had better conform to and slightly higher than the local standards, so as to attract and retain talents. Multinational enterprises shall make their compensation strategy on a basis of local labor costs, law and trade unions' requirement. Second, the diversification of welfare system is contributed to attract talents and reach their potential, such as: organize basketball match, paid vacation, collective tourism, etc.

\section{G. Training system integration}

Human resources have very strong plasticity. Training, not only can improve the efficiency of enterprise production, but also can improve employees' loyalty.

First of all, supply professional skills training to employees. In the transitional enterprises, investment fund flows, so does the technology. However, the employees from host country don't know much about the new production technology, so training is essential for them to be competent at work. Second, supply cross-cultural training. Cross-cultural training mainly includes language skills, cultural empathy, decision-making ability and so on. This is beneficial for all personnel to get spiritual guidance, improve the enterprise's centripetal force and cohesion, and enhance the company's international competitiveness.

\section{CONCLUSIONS}

Today, with economic globalization, China and Thailand are moving to more scientific and user-friendly direction in the human resources management. Chinese enterprises investing in Thailand need to pay attention to the similarities and differences in the human resource management between the two countries. As attracting, recruiting, retaining employees or designing personnel incentive mode, we must take the Thai 
staff's unique life attitude and behavior into consideration. By building the harmonious interpersonal relationship, abiding by the labor protection law of Thailand, and establishing good industrial and labor relations, only in this way can we ensure that human resources management of China's enterprises can achieve success in Thailand.

\section{ACKNOWLEDGMENT}

This work was supported by my teacher-Liyan, the papers from the selected topic to finish, every step is done under the guidance of my teacher, teacher spent a lot of time and energy to this papers, here, I want to express my deep gratitude and blessings to liyan teacher.

\section{REFERENCES}

[1] "Statistical Bulletin of China's Outward Foreign Direct Investment," 2012.

[2] R.L. Li, "Promote the Sustainable Development Strategy of Chinese."

[3] G. Hofstede, G.J. Hofstede, "Cultures and Organizations: software of the mind," NY: Mc Graw Hill, 2005.

[4] X.X. Dai, "Analysis on Cultural Differences between China and Thailand from the Movie Lost in Thailand," Chinese Times, 2013.

[5] Y.J. Han, "International Business," Peking: Renmin University of China, 2011.

[6] W.L. Charles, "Hill. International Business," Peking: Renmin University of China, 2012.

[7] Z.Y. Hu, and X.F. Dong, "The Comparison of Human Resource Management between China and Thailand," Around Management, 2012.

[8] Y.H. Chen, "The Primary of Enterprise's Human Resources Management under Cultural Differences," Taking China's and Thailand's Culture Comparison as An Example, Journal of Taiyuan City Vocational and Technical College, 2008. 